\title{
Individual risk assessment and information technology to optimise screening frequency for diabetic retinopathy
}

\author{
T. Aspelund • Ó. Pórisdóttir • E. Ólafsdottir • A. Gudmundsdottir • A. B. Einarsdóttir • \\ J. Mehlsen • S. Einarsson • Ó. Pálsson • G. Einarsson • T. Bek • E. Stefánsson
}

Received: 8 July 2010 /Accepted: 26 May 2011 / Published online: 27 July 2011

(C) Springer-Verlag 2011

\begin{abstract}
Aims/hypothesis The aim of this study was to reduce the frequency of diabetic eye-screening visits, while maintaining safety, by using information technology and individualised risk assessment to determine screening intervals.

Methods A mathematical algorithm was created based on epidemiological data on risk factors for diabetic retinopathy.
\end{abstract}

Ó. Pórisdóttir and E. Ólafsdottir contributed equally to this study.

Electronic supplementary material The online version of this article (doi:10.1007/s00125-011-2257-7) contains peer-reviewed but unedited supplementary material, which is available to authorised users.

T. Aspelund · E. Ólafsdottir · A. B. Einarsdóttir •

E. Stefánsson $(\bowtie)$

Faculty of Medicine, University of Iceland,

Reykjavik, Iceland

e-mail: einarste@landspitali.is

T. Aspelund · Ó. Pórisdóttir · A. Gudmundsdottir •

A. B. Einarsdóttir · S. Einarsson • Ó. Pálsson · G. Einarsson •

T. Bek $\cdot$ E. Stefánsson

Risk Medical Solutions,

Reykjavik, Iceland

Ó. Pórisdóttir

Aarhus University,

Aarhus, Denmark

E. Ólafsdottir • A. Gudmundsdottir • A. B. Einarsdóttir ·

G. Einarsson · E. Stefánsson

University of Iceland, National University Hospital,

101 Reykjavík, Iceland

J. Mehlsen • T. Bek

Aarhus University Hospital,

Aarhus, Denmark

E. Stefánsson

King Saud University,

Riyadh, Saudi Arabia
Through a website, www.risk.is, the algorithm receives clinical data, including type and duration of diabetes, $\mathrm{HbA}_{1 \mathrm{c}}$ or mean blood glucose, blood pressure and the presence and grade of retinopathy. These data are used to calculate risk for sight-threatening retinopathy for each individual's worse eye over time. A risk margin is defined and the algorithm recommends the screening interval for each patient with standardised risk of developing sightthreatening retinopathy (STR) within the screening interval. We set the risk margin so that the same number of patients develop STR within the screening interval with either fixed annual screening or our individualised screening system. The database for diabetic retinopathy at the Department of Ophthalmology, Aarhus University Hospital, Denmark, was used to empirically test the efficacy of the algorithm. Clinical data exist for 5,199 patients for 20 years and this allows testing of the algorithm in a prospective manner.

Results In the Danish diabetes database, the algorithm recommends screening intervals ranging from 6 to 60 months with a mean of 29 months. This is $59 \%$ fewer visits than with fixed annual screening. This amounts to 41 annual visits per 100 patients.

Conclusion Information technology based on epidemiological data may facilitate individualised determination of screening intervals for diabetic eye disease. Empirical testing suggests that this approach may be less expensive than conventional annual screening, while not compromising safety. The algorithm determines individual risk and the screening interval is individually determined based on each person's risk profile. The algorithm has potential to save on healthcare resources and patients' working hours by reducing the number of screening visits for an ever increasing number of diabetic patients in the world. 
Keywords Diabetes mellitus - Diabetic retinopathy. Risk assessment $\cdot$ Screening

\section{Abbreviations}

ROC Receiver operating characteristic

STR Sight-threatening retinopathy

\section{Introduction}

From a public health standpoint, screening for diabetic eye disease is one of the most cost effective preventative health procedures available [1-3]. Annual examinations are standard in most diabetic eye-screening programmes and recommended by the World Health Organization and most health authorities and organisations involved in diabetes and ophthalmology [4-6]. As the prevalence of diabetes mellitus worldwide is rising and with it the total cost of screening, it becomes more important to make screening programmes as effective as possible [7].

With a fixed interval between screening visits, the interval is the same for all, whereas the risk of developing sight-threatening retinopathy (STR) between screening visits is individually variable. Some patients are at high risk of developing STR and requiring treatment before the next screening visit, whereas for others this risk would be low. The fixed screening interval must be geared towards patients at relatively high risk; otherwise they might go blind. The fixed 'one size fits all' approach to screening leaves room for improvement. By basing the screening interval on each patient's risk margin, it should be possible to increase screening frequency for those at high risk and thereby increase their safety and at the same time reduce the screening frequency for patients at low risk and reduce expenditure on healthcare costs and patients' time (Fig. 1). Indeed, such an approach might apply to a variety of diseases.

In 1991 Dasbach and associates examined various approaches to screening for diabetic retinopathy [8]. In 1993, Kalm and Jonsson [9] proposed variable screening intervals based on risk margins and in 1994 the Icelandic screening programme moved in this direction by lengthening the screening interval to 2 years for diabetic patients without retinopathy [10]. This approach has proven to be safe and effective [11], and has been adopted by many diabetic eyescreening programmes. Classifying risk margins based on broad classification, such as presence or absence of retinopathy, is easily mastered by the busy clinician and is traditional in medicine. This approach can be improved dramatically by taking into account more risk factors in a quantitative way with the help of information technology.

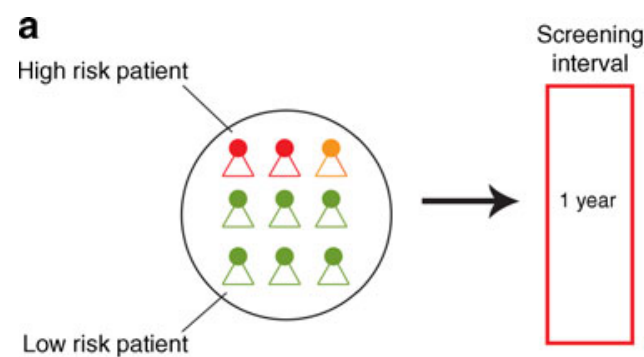

b

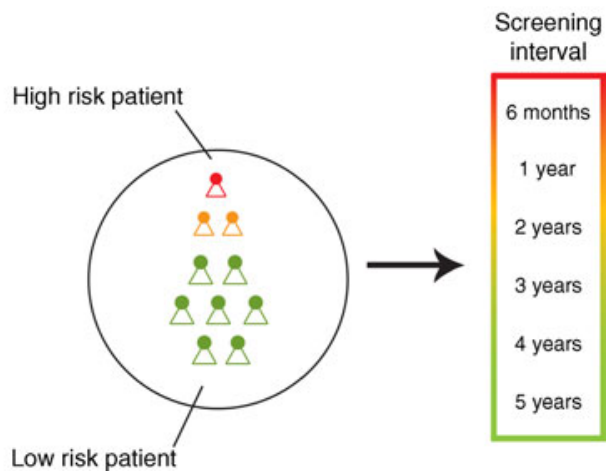

Fig. 1 The schematic drawings illustrate the conceptual difference between fixed annual screening and the individualised approach to diabetic eye screening. a Annual screening: the group of diabetic patients with variable risk for sight-threatening diabetic retinopathy. Red indicates high risk, yellow, medium and green, low risk. All have fixed 12 month screening intervals. However, their risk of developing sight-threatening diabetic retinopathy within the year is vastly different. This is the 'one size fits all' approach. b The individualised screening: again the group of diabetic patients with variable risk is depicted. Here the screening interval is based on the individual risk. Patients at high risk are screened more frequently, up to every 6 months, whereas patients at low risk are screened less frequently, down to every 5 years

The risk factors for incidence and progression of diabetic retinopathy are well known and include duration and type of diabetes, mean blood glucose or $\mathrm{HbA}_{1 \mathrm{c}}$, systolic blood pressure, and presence of retinopathy [12-18]. On the basis of these risk factors it is possible to calculate the individual risk for the development and progression of diabetic retinopathy. While a quantitative calculation based on five or six variables cannot easily be made by the busy clinician, a mathematical algorithm in a computer can do so in seconds. The individual risk for progression to sightthreatening retinopathy (STR) is a sound foundation for recommending an appropriate screening interval for the individual patient, where the risk margin for developing STR (diabetic macular oedema or proliferative diabetic retinopathy) within the screening interval is pre-determined.

In this study we use a mathematical algorithm based on known risk factors to obtain an individualised risk assessment, which is used to determine screening intervals for diabetic retinopathy. The purpose is to standardise individual risk, use the risk assessment to control screening intervals and make screening programmes more effective. 


\section{Methods}

A mathematical algorithm to compute the risk of STR was created based on: (1) epidemiological data for the prevalence of diabetic retinopathy from the Icelandic eye-screening database [18-21]; and (2) on risk factors from published reports [12-17] (Table 1). Individual or personal data was not considered in the creation of the algorithm, whereas individual data from the Aarhus diabetic database was used in the empirical testing (see below).

The risk function was based on the Weibull proportional hazards model. The model has two parts: (1) the baseline cumulative probability of STR; and (2) the relative risks associated with risk factors. It is a standard parametric survival function and has, for example, been used in the SCORE project of the European Society of Cardiology to estimate cardiovascular risk [22]. From this model the baseline survival probability for being free of disease, that is, STR, has the form $S_{0}(t)=\exp \left[-\exp (\alpha) t^{p}\right]$, where $t$ is the time from onset (duration) of diabetes and $\exp ()$ is the exponential function. The values of $\alpha$ and $p$ define the shape of the survival function and provide flexibility to accurately describe collected survival data. The baseline survival probability of STR is 1 minus the probability of being free of STR or $F_{0}(t)=1-S_{0}(t)=1-\exp \left[-\exp (\alpha) t^{p}\right]$.

The variables $\alpha$ and $p$, to define $S_{0}(t)$, were found separately for type 1 and type 2 diabetes by fitting $F_{0}(t)$ to epidemiological data on STR in Iceland [18-21]. The nlminb optimisation routine in $\mathrm{R}$, for non-linear curve estimation, was used for fitting of $F_{0}(t)$ with results displayed in Fig. 2 [23]. For type 1 diabetes we found that $F_{0}(t)=1-\exp \left[-\exp (-7.849) t^{2.075}\right]$ and for type 2 we

Table 1 Major risk factors and their risk ratios for progression of diabetic retinopathy used in our project, and citations for relevant epidemiological studies

\begin{tabular}{|c|c|c|c|}
\hline Variable & $\begin{array}{l}\text { Risk } \\
\text { ratio }\end{array}$ & $95 \% \mathrm{CI}$ & Reference \\
\hline \multicolumn{4}{|l|}{ Type 1 diabetes } \\
\hline $\mathrm{HbA}_{1 \mathrm{c}}(\%)$ & 1.20 & $1.16,1.25$ & [14] \\
\hline Systolic BP $(10 \mathrm{mmHg})$ & 1.08 & $1.04,1.12$ & [14] \\
\hline \multicolumn{4}{|l|}{ NPDR } \\
\hline Female & 2.74 & NA & {$[14,15]$} \\
\hline Male & 3.30 & NA & {$[14,15]$} \\
\hline \multicolumn{4}{|l|}{ Type 2 diabetes } \\
\hline $\mathrm{HbA}_{1 \mathrm{c}}(\%)$ & 1.46 & $1.05,2.02$ & [13] \\
\hline Systolic BP $(10 \mathrm{mmHg})$ & 1.54 & $1.06,2.27$ & [12] \\
\hline \multicolumn{4}{|l|}{ NPDR } \\
\hline Female & 1.78 & NA & {$[15,16]$} \\
\hline Male & 3.30 & NA & {$[15,16]$} \\
\hline
\end{tabular}

NPDR, nonproliferative diabetic retinopathy
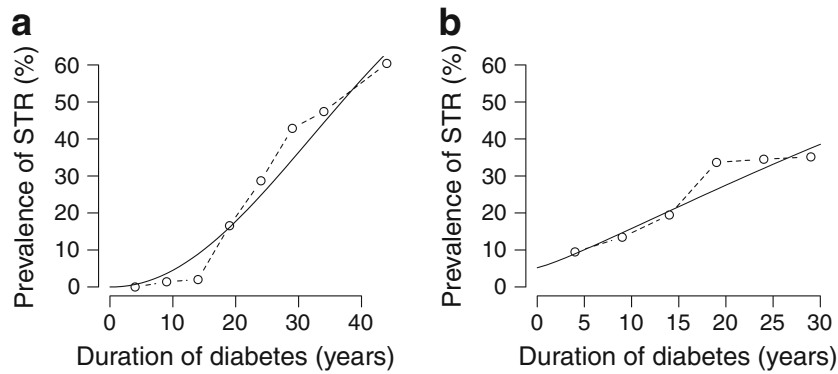

Fig. 2 Prevalence of STR by duration of diabetes. Prevalence data from the Icelandic diabetic population (dashed line/circles) with fitted Weibull cumulative probability curve (solid line). a Prevalence for type 1 diabetes. b Prevalence for type 2 diabetes

found that $F_{0}(t)=1-\left[\exp \left(-\exp [-4.88] t^{1.170}\right)-0.052\right]$. For type 2 we used an offset of 0.052 in risk because it was estimated that $5.2 \%$ of newly diagnosed participants had already developed STR [18].

Proportional hazards were assumed, as is typical for risk models and was assumed in the analysis of the UK Prospective Diabetes Study (UKPDS) and Wisconsin data [12-14, 17], to generate personalised estimates of 'survival' free from STR by exponentiating $S_{0}(t)$ with a linear combination of established risk factors and relative risk variables so that the individual survival was $S(t)=S_{0}(t)^{\exp (\text { linear combination) }}$. For type 1 diabetes the linear combination used had the form:

$$
\begin{aligned}
& \left(\mathrm{HbA}_{1 \mathrm{c}}[\%]-8\right) \times 0.1851+(\mathrm{sbp}-130) \times 0.007813 \\
& \quad+(\text { DRpresent }-0.52) \times\left(1.1+\beta_{\mathrm{DR}}\right)
\end{aligned}
$$

where $\beta_{\mathrm{DR}}=0.194$ for men and $\beta_{\mathrm{DR}}=-0.194$ for women when DR is present and $\beta_{\mathrm{DR}}=0$ otherwise. Here sbp stands for systolic blood pressure and DRpresent $=1$ if diabetic retinopathy was present and DRpresent $=0$ otherwise. For type 2 diabetes, the linear combination was

$$
\begin{aligned}
& \left(\mathrm{HbA}_{1 \mathrm{c}}[\%]-8\right) \times 0.380544+(\mathrm{sbp}-130) \times 0.04308 \\
& \quad+(\text { DRpresent }-0.33) \times\left(0.89+\beta_{\mathrm{DR}}\right),
\end{aligned}
$$

where $\beta_{\mathrm{DR}}=0.46$ for men and $\beta_{\mathrm{DR}}=-0.46$ for women if diabetic retinopathy was present and $\beta_{\mathrm{DR}}=0$ otherwise. The linear combination was centred on mean values of $\mathrm{HbA}_{1 \mathrm{c}}$ and systolic blood pressure in the Icelandic diabetic population, namely $8 \%(64 \mathrm{mmol} / \mathrm{mol})$ and $130 \mathrm{mmHg}$ respectively, and the prevalence of diabetic retinopathy for type 1 diabetes was $52 \%$, and for type 2 diabetes was $33 \%$. This was done to calibrate the risk so that $F_{0}(t)$ defined the average risk in the population.

The risk of developing STR in a time interval $\Delta t$, for a retinopathy free individual with given risk factor values and $t$ as the duration of diabetes at time $t$, was then computed as:

$\operatorname{risk}(\Delta t \mid$ disease free at $t)=1-S(t+\Delta t) / S(t)$ 
To compute the time interval $\Delta t$ when the risk would reach a value $r$, between 0 and 1 , the equation:

$\operatorname{risk}(\Delta t \mid$ disease free at $\mathrm{t})=r$

was solved for $\Delta t$. The solution $\Delta t$ was then used as the recommended maximum screening time for the patient before the risk would reach the risk margin, $r$.

Through a website, www.risk.is, the algorithm receives clinical data including type and duration of diabetes, $\mathrm{HbA}_{1 \mathrm{c}}$ or mean blood glucose, blood pressure and the presence and grade of retinopathy (see electronic supplementary material [ESM] Fig. 1). These data are used to calculate risk for STR for each individual's worse eye over a given time span. An acceptable risk margin is defined and the algorithm recommends the screening interval for each patient, i.e. when (s)he should next be seen in the screening clinic. For empirical testing the risk margin was set so that the number of individuals with STR at the next screening visit was equal with our algorithm and fixed annual screening. In the Aarhus database 149 patients out of 5,199 developed STR during their first year in the screening programme. This amounts to $2.9 \%$ and the risk margin in our algorithm was set at $3.2 \%$ to match this rate. The risk margin is slightly higher because of the difference in mean risk between the Aarhus data and the Icelandic population data.

Empirical testing for safety and efficacy of the algorithm was performed using patient records in the database for diabetic retinopathy at the Department of Ophthalmology, Aarhus University Hospital, Denmark. The database is described in detail by Mehlsen et al. [24, 25]. Prospectively accumulated clinical data, fundus photographs and information on outcome are available for 5,199 patients over 20 years and this allows testing of the algorithm in a prospective manner.

Receiver operating characteristics (ROC) analysis of the diagnostic capacity of the algorithm was performed using the roc package in the statistical program $\mathrm{R}$ [23].

For each patient in the database the risk of STR was calculated at the first recorded visit in the database. This risk level was used to determine the recommended screening interval, $\Delta t$, for the first interval alone. The clinical outcome as recorded in the database was used to empirically find whether each individual patient developed STR within the recommended interval.

Missing values in the Aarhus database were handled as follows: missing blood pressure values were set at $130 \mathrm{mmHg}$ and $\mathrm{HbA}_{1 \mathrm{c}}$ at $8 \%(64 \mathrm{mmol} / \mathrm{mol})$. There were missing values for blood pressure for a total of 3,492 patients $(67 \%)$ out of 5,199 patients. There were missing values for $\mathrm{HbA}_{1 \mathrm{c}}$ for 1,131 patients $(22 \%)$ out of 5,199 patients. Individual data for duration of diabetes, sex, and presence of diabetic retinopathy or STR were available for all patients.
For clinical use it was decided to impose a 6 month floor and 60 month ceiling to screening intervals.

\section{Results}

Testing the algorithm in the Aarhus diabetic database indicates that the mean recommended screening interval is 29 months. The reduction in screening frequency is $59 \%$ compared with fixed annual screening; $2.9 \%$ of the patients developed STR before the next screening visit.

ESM Fig. 1 shows a computer screen shot and an example of how the algorithm is used for an individual patient. The patient's clinical data are entered in the panel and the graph shows this patient's risk of developing STR over time. The algorithm recommends that this patient be screened again after 24 months, as is shown in red on the computer screen.

Figure 3 shows the recommended screening interval for type 1 and 2 diabetes patients with variable risk profiles as determined by their risk factors. The screening interval is limited by the 6 month floor and 60 month ceiling and varies according to individual risk. The risk profiles for individual diabetic patients are highly variable. The mean screening interval is 29 months and the median is 23 months. The first quartile for the screening interval is 11 months and the third quartile is 49 months.

Figure $4 \mathrm{a}$ shows a ROC curve, and the area under the curve was found to be $0.76(95 \%$ CI $0.74,0.78)$. This number indicates that there is a $76 \%$ probability that a randomly selected patient who develops STR will be given a higher risk score than a randomly selected patient who does not develop STR. Figure $4 \mathrm{~b}$ shows a calibration graph, showing the observed fraction of STR events within each decile of estimated risk.

\section{Discussion}

This is the first report to present a mathematical algorithm, based on epidemiological data on risk factors for diabetic retinopathy, to determine screening intervals for diabetic eye disease. Empirical testing in the Danish database suggests that this approach gets the same results with fewer screening examinations than the fixed annual screening programmes currently in use. With the standard risk margin the number of screening visits is reduced by $59 \%$ compared with annual screening, with the same number of patients developing STR before the next screening visit. This reduces the cost for screening programmes and improves utilisation of healthcare resources.

Regular screening and preventive treatment for diabetic retinopathy is a powerful tool to reduce blindness. In 
Fig. 3 Screening time (months) by type of diabetes, $\mathrm{HbA}_{1 \mathrm{c}}$, systolic blood pressure, diabetic retinopathy (DR; including proliferative retinopathy [PDR]) and sex. The figure shows the recommended screening interval for patients with variable risk profiles as determined by their risk factors. A 6 month floor and a 60 month ceiling is applied and the screening interval ranges from 6 months in high-risk individuals to 5 years for those at low risk. Recommended screening intervals are shown in (a) for type 1 diabetes patients and in (b) for type 2 diabetes patients. Red, $\leq 6$ months; orange, 7-12 months; yellow, 13-24 months; light green, 25-36 months; dark green, 3748 months; blue, $\geq 49$ months. To convert values for $\mathrm{HbA}_{1 \mathrm{c}}$ in $\%$ to $\mathrm{mmol} / \mathrm{mol}$, subtract 2.15 and multiply by 10.929 a

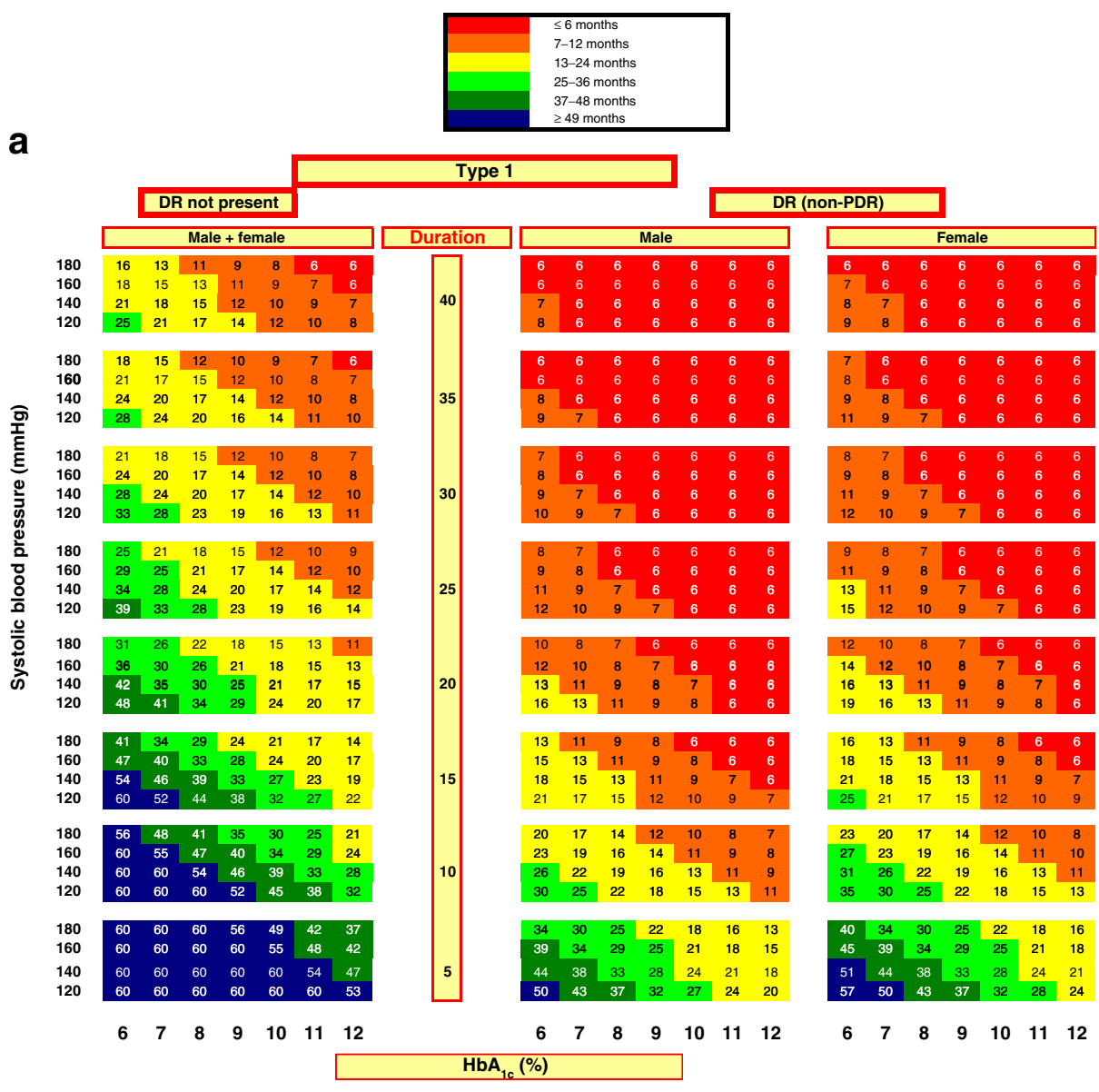

b

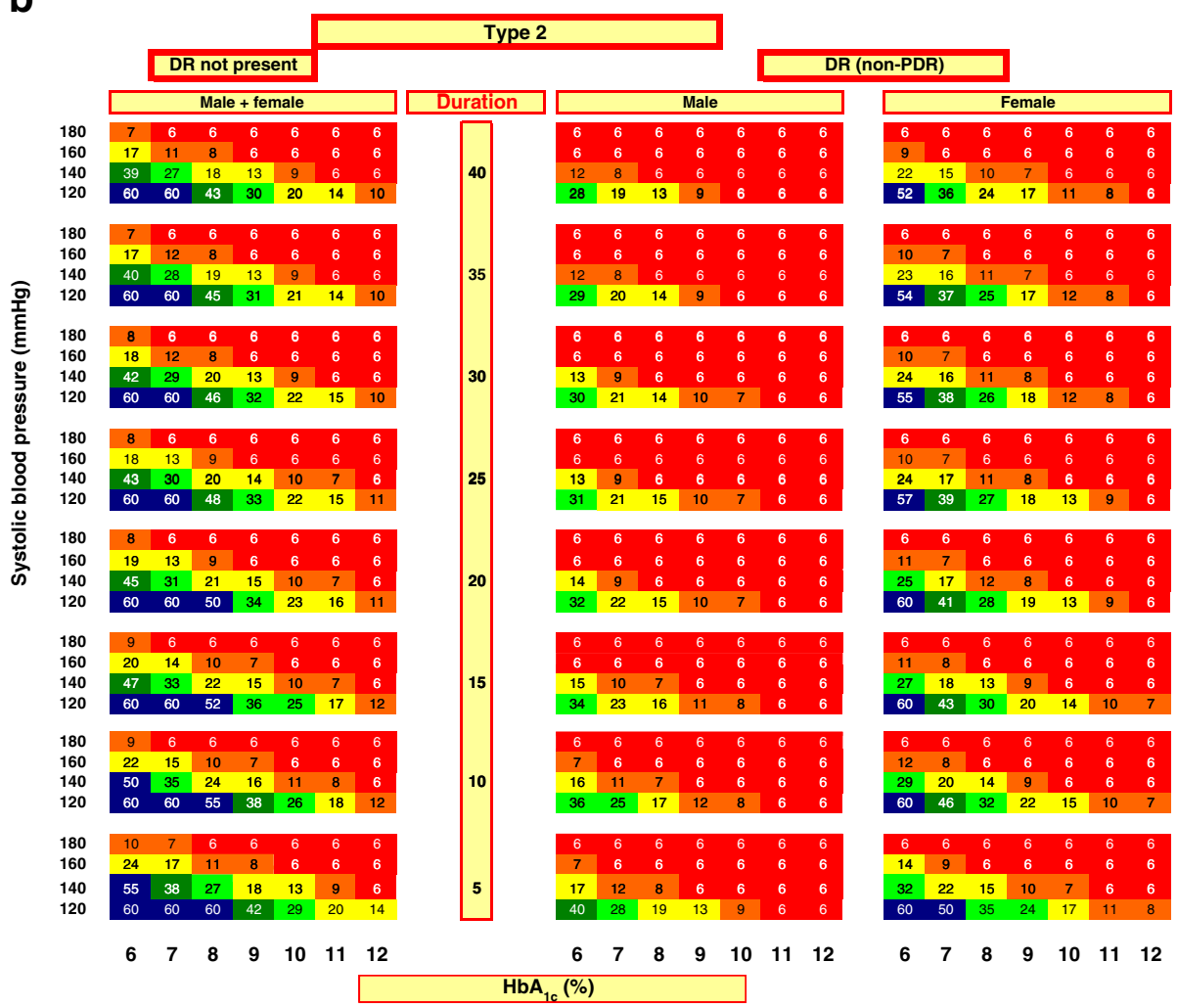



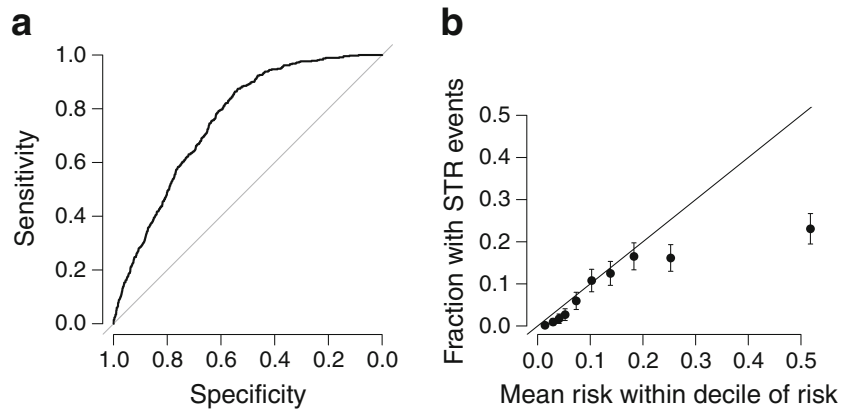

Fig. 4 a ROC curve, with area under the curve of 0.76 (95\% CI 0.74 , 0.78). b Calibration graph, showing observed fraction of STR events within each decile of estimated risk. The error bars represent $95 \% \mathrm{CI}$

Iceland, the prevalence of blindness within the diabetic population decreased from $2.4 \%$ to $0.5 \%$ following the onset of screening in 1980, and this is largely attributable to the public health programme $[2,10,18-21,26]$. Comparable success has been seen with similar programmes in Sweden and Denmark [27-29].

The list of risk factors includes type and duration of diabetes, $\mathrm{HbA}_{1 \mathrm{c}}$, systolic blood pressure, sex, and the presence and grade of retinopathy. These factors have been reported to predict the development of retinopathy (Table 1). It is an advantage that the algorithm uses only a few risk factors, which makes it easy to use for the patient or the clinician. Mean blood glucose is the number that appears on the blood sugar meter when turned on and could be used as a substitute for $\mathrm{HbA}_{1 \mathrm{c}}$ in cases where the $\mathrm{HbA}_{1 \mathrm{c}}$ is unknown by the patient. Using a mean weighted $\mathrm{HbA}_{1 \mathrm{c}}$ would be a better and a more accurate way of estimating blood sugar control than using $\mathrm{HbA}_{1 \mathrm{c}}$ at a single point in time, since these values are not constant for an individual patient. In practice we would recommend that physicians calculate a mean of the last three $\mathrm{HbA}_{1 \mathrm{c}}$ measurements for each individual patient to give a recommendation on the screening interval. If an individual patient has $\mathrm{HbA}_{1 \mathrm{c}}$ measurements in a wide range it would also be recommended to go with the worst case scenario and use the highest $\mathrm{HbA}_{1 \mathrm{c}}$ level.

For example, a male patient with type 2 diabetes with duration of 10 years, blood pressure of 130/80 mmHg and no known retinopathy would have a screening interval of 53 months with $\mathrm{HbA}_{1 \mathrm{c}}$ of $7 \%(53 \mathrm{mmol} /$ mol). This would change to 17 months if $\mathrm{HbA}_{1 \mathrm{c}}$ increased to $10 \%(86 \mathrm{mmol} / \mathrm{mol})$. For a similar patient with 20 year duration of diabetes, the recommended screening interval would be 47 months with $\mathrm{HbA}_{1 \mathrm{c}}$ of $7 \%(53 \mathrm{mmol} / \mathrm{mol})$ and only 15 months with $\mathrm{HbA}_{1 \mathrm{c}}$ of $10 \%(86 \mathrm{mmol} / \mathrm{mol})$. We expect that each diabetic patient be followed up on a regular basis by his diabetologist or general practitioner. Should the patient's risk factors change over time, the risk analysis and recommendation for the screening interval should be adjusted.

Gross proteinuria is a risk indicator of proliferative diabetic retinopathy in younger-onset patients but the relationship was of borderline statistical significance in a population-based study in Wisconsin [30]. Proteinuria may not be strongly predictive for the development of retinopathy and we do not use proteinuria as a predictor in our algorithm. Somewhat counter-intuitively, smoking status was inversely related to the development of new lesions and progression of established retinopathy in the UKPDS50 study [16]. In spite of this data we opted not to include smoking in the risk calculator due to the deleterious effects of smoking in terms of cardiovascular and lung cancer risk that would far outweigh the retinopathy risk reduction in terms of total morbidity.

This study can be seen as an extension of our earlier studies $[10,11]$, which show that alternate year screening for diabetic eye disease seems to be safe and effective in diabetic patients without retinopathy and, by doing this, the financial savings are substantial. In this study we have gone further and used information technology and available epidemiological studies to standardise the risk and make individual determinations of screening intervals for diabetic eye disease. This makes screening programmes more focused and less expensive. In the early days of diabetic eye screening, Dasbach [8] suggested that cost effectiveness of screening could be improved by selectively targeting high-risk groups of the diabetic population. This was followed by the work of Kalm and Jonsson [9], who also used modelling work to suggest that diabetic screening intervals could be varied and lengthened based on the risk profile of diabetic patients.

We face a global epidemic of diabetes [31, 32], where the number of patients with diabetes in the world is estimated to increase from 171 million in 2000 to at least 366 million in 2030 [7]. While public health programmes for diabetic eye screening are very effective and indeed highly cost effective [1], they are expensive to operate, owing to the very large number of patients. The cost per screening visit in the ophthalmologist-based Icelandic screening system is approximately 53 euros, and the cost involved in photographic screening programmes in Europe is $30-40$ euros. Let us assume that each screening visit in developed countries costs 40 euros and the visit and travel takes 2 working hours of the patient' time. Annual screening for 1 million diabetic patients would cost 40 million euros and 2 million working hours and this cost could be reduced by $59 \%$ with our algorithm. Wild et al. [7], estimate the prevalence of diabetes in the USA to be 18 million in 2000 and 30 million in 2030 and it is reasonable to assume that Europe's somewhat larger population is similar, and we will estimate the current number at 25 million 
diabetic patients in each region. In this case, either Europe or the USA would each require about 1 billion euros and 50 million working hours annually to conduct a fixed annual diabetic eye-screening programme. Individualised risk assessment and screening in Europe or the USA could save 580 million euros and 29 million working hours each year in each region. In both cases the benefit of reduced prevalence of blindness would far outweigh the cost of screening [1].

Our algorithm is based on large international studies on diabetic retinopathy [12-18], and published literature on the epidemiology of diabetic retinopathy was considered. Our algorithm is based on the Icelandic population and it was tested empirically in a Danish population. Both are white with Nordic heritage. While this gives us reasonable confidence in our conclusion, further testing in other populations would be valuable, particularly in order to extend these results to populations of different ethnicity.

The Aarhus database represents prospectively accumulated data of diabetic patients over 20 years. This database allows empirical testing of the outcome for the algorithm based on actual data from actual patients with recorded data at reported time points. A large prospective study is desirable for further testing of our protocol.

The distribution of screening intervals is shown in Fig. 3. Here, the 6 month floor and 60 month ceiling is applied, which removes the extremes in screening intervals.

The area under the ROC curve in Fig. 4a was 0.76 , which represents an acceptable diagnostic capacity and is within the range typical for risk models for cardiovascular disease [33].

Figure $4 \mathrm{~b}$ demonstrates that the algorithm tends to overestimate the risk, especially for high risk. This may be due to a number of factors. In our algorithm we assume that the risk factors are independent, which may not be exact. Also, we assume that the risk factors have a linear effect over the entire range, which may not apply for high values. Third, some of the patients with high-risk characteristics may have received treatment to improve the risk factors such as blood glucose and blood pressure. Fourth, in a relatively large group of patients, default values had to be applied for blood pressure and this could also be responsible for some errors. And last, the baseline cumulative prevalence in our data may not be directly transferable to a new population. Simple calibration methods, such as suggested by van Houwelingen [34], could be applied to the risk function to refine the adaptation to the population using the algorithm. The observed fraction of STR events by deciles of risk would then be seen to be closer to the diagonal in Fig. 4b. This has no effect on risk ranking in the database and therefore the diagnostic capacity of the algorithm stays the same.

Eye screening and preventive treatment for the 200-300 million diabetic patients in the world would substantially decrease the global burden of blindness [1-3]. Such screening is still a distant dream, in spite of 20 years of goals and plans by major medical organisations. One reason for the lack of success is the considerable cost of such a programme and the lack of resources, both money and manpower. Our information technology can decrease the costs by more than half and help make global diabetic eye screening economically feasible. The basic approach used in this project could be applied to other disease categories and healthcare delivery. Information technology based on available epidemiological data opens the way to individualised allocation of healthcare resources, which will make healthcare more economical and more effective in general.

Acknowledgements This work has been presented in part at the annual meeting of the Association for Research in Vision and Ophthalmology in Ft. Lauderdale USA on 3 May 2010 and at the annual meeting of The European Association for the Study of Diabetes, Eye Complications in Paris on 22 May 2010. The algorithm has been developed by a research company, Risk ehf. in Reykjavík, Iceland with the support of The Icelandic Research Council, Technological Development Fund.

Duality of interest The authors are related to the research company Risk ehf. in the following ways: E. Ólafsdottir, shareholder and cofounder; Ó. Pórisdóttir, part-time employee; T. Aspelund, shareholder and co-founder, consultant; A. Gudmundsdottir, shareholder and cofounder, A. Bryndís Einarsdóttir, shareholder, former part-time employee; S. Einarsson, shareholder and co-founder; Ó. Pálsson, employee, shareholder; G. Einarsson, former part-time employee; T. Bek, consultant; E. Stefánsson, shareholder and founder. Additional grant support was given by The Icelandic Centre for Research: Students Innovation Fund and The Directorate of Labour. J. Mehlsen has no duality of interest associated with this manuscript.

Contribution statement T.A. contributed to writing the paper, designed the mathematical algorithm and analysed the data; Ó.P. contributed to writing the paper and took part in designing and implementing the mathematical algorithm for analysis of the data; E.Ó. took part in developing the concept and contributed to writing the paper; A.G. took part in developing and testing the concept and writing of the paper; A.B.E. took part in developing the concept, analysing clinical epidemiological information and drafting of the paper; J.M. took part in clinical testing and analysis of clinical data in Denmark and initial drafting of the paper; S.E. designed and wrote computer software and assisted in writing; Ó.P. contributed to writing the paper, developing the concept and overall organisation; G.E. analysed and accumulated epidemiological information and took part in initial drafting of the paper; T.B. undertook clinical testing and analysis of clinical data in Denmark and took part in developing the concept and the initial drafting of the paper; E.S. originated the concept, gathered the research group, contributed to overall organisation, designed the study, contributed to writing the paper and analysis of the data. All authors approved the final version of the manuscript.

\section{References}

1. Javitt JC, Aiello LP, Chiang Y, Ferris FL 3rd, Canner JK, Greenfield S (1994) Preventive eye care in people with diabetes 
is cost-saving to the federal government. Implications for healthcare reform. Diabetes Care 17:909-917

2. Stefansson E, Bek T, Porta M, Larsen N, Kristinsson JK, Agardh E (2000) Screening and prevention of diabetic blindness. Acta Ophthalmol Scand 78:374-385

3. Tung TH, Shih HC, Chen SJ, Chou P, Liu CM, Liu JH (2008) Economic evaluation of screening for diabetic retinopathy among Chinese type 2 diabetics: a community-based study in Kinmen, Taiwan. J Epidemiol 18:225-233

4. Backlund LB, Algvere PV, Rosenqvist U (1997) New blindness in diabetes reduced by more than one-third in Stockholm County. Diabet Med 14:732-740

5. Piwernetz K, Home PD, Snorgaard O, Antsiferov M, StaehrJohansen K, Krans M (1993) Monitoring the targets of the St Vincent Declaration and the implementation of quality management in diabetes care: the DIABCARE initiative. The DIABCARE Monitoring Group of the St Vincent Declaration Steering Committee. Diabet Med 10:371-377

6. Scanlon PH (2008) The English national screening programme for sight-threatening diabetic retinopathy. J Med Screen 15:1-4

7. Wild S, Roglic G, Green A, Sicree R, King H (2004) Global prevalence of diabetes: estimates for the year 2000 and projections for 2030. Diabetes Care 27:1047-1053

8. Dasbach EJ, Fryback DG, Newcomb PA, Klein R, Klein BE (1991) Cost effectiveness strategies for detecting diabetic retinopathy. Med Care 29(1):20-39

9. Kalm H, Jonsson R (1993) Diabetic retinopathy screening. University of Gothenburg, Gothenburg

10. Kristinsson JK, Gudmundsson JR, Stefansson E, Jonasson F, Gislason I, Thorsson AV (1995) Screening for diabetic retinopathy. Initiation and frequency. Acta Ophthalmol Scand 73:525-528

11. Olafsdottir E, Stefansson E (2007) Biennial eye screening in patients with diabetes without retinopathy: 10-year experience. $\mathrm{Br}$ J Ophthalmol 91:1599-1601

12. UK Prospective Diabetes Study Group (1998) Tight blood pressure control and risk of macrovascular and microvascular complications in type 2 diabetes: UKPDS 38. BMJ 317:703-713

13. UK Prospective Diabetes Study (UKPDS) Group (1998) Intensive blood-glucose control with sulphonylureas or insulin compared with conventional treatment and risk of complications in patients with type 2 diabetes (UKPDS 33). Lancet 352:837-853

14. Klein R, Klein BE, Moss SE, Cruickshanks KJ (1998) The Wisconsin Epidemiologic Study of Diabetic Retinopathy: XVII. The 14-year incidence and progression of diabetic retinopathy and associated risk factors in type 1 diabetes. Ophthalmology 105:1801-1815

15. Kohner EM, Stratton IM, Aldington SJ, Holman RR, Matthews DR (2001) Relationship between the severity of retinopathy and progression to photocoagulation in patients with type 2 diabetes mellitus in the UKPDS (UKPDS 52). Diabet Med 18:178-184

16. Stratton IM, Kohner EM, Aldington SJ et al (2001) UKPDS 50: risk factors for incidence and progression of retinopathy in type II diabetes over 6 years from diagnosis. Diabetologia 44:156-163
17. Prospective UK (1991) Diabetes study (UKPDS). VIII. Study design, progress and performance. Diabetologia 34:877-890

18. Kristinsson JK (1997) Diabetic retinopathy. Screening and prevention of blindness. A doctoral thesis. Acta Ophthalmol Scand Suppl 223:1-76

19. Kristinsson JK, Hauksdottir H, Stefansson E, Jonasson F, Gislason I (1997) Active prevention in diabetic eye disease. A 4-year follow-up. Acta Ophthalmol Scand 75:249-254

20. Kristinsson JK, Stefansson E, Jonasson F, Gislason I, Bjornsson S (1994) Screening for eye disease in type 2 diabetes mellitus. Acta Ophthalmol (Copenh) 72:341-346

21. Kristinsson JK, Stefansson E, Jonasson F, Gislason I, Bjornsson S (1994) Systematic screening for diabetic eye disease in insulin dependent diabetes. Acta Ophthalmol (Copenh) 72:72-78

22. Conroy RM, Pyörälä K et al (2002) Estimation of ten-year risk of fatal cardiovascular disease in Europe: the SCORE project. Eur Heart J 24:987-1003

23. R Development Core Team (2009) A language and environment for statistical computing. Available from www.R-project.org. Accessed 1 July 2011

24. Mehlsen J, Erlandsen M, Poulsen PL, Bek T (2009) Identification of independent risk factors for the development of diabetic retinopathy requiring treatment. Acta Ophthalmol. doi:10.1111/ j.1755-3768.2009.01.742.x

25. Mehlsen J, Erlandsen M, Poulsen PL, Bek T (2010) Individualized optimization of the screening interval for diabetic retinopathy: a new model. Acta Ophthalmol. doi:10.1111/j.1755-3768.2010.01882.x

26. Zoega GM, Gunnarsdottir T, Bjornsdottir S, Hreietharsson AB, Viggosson G, Stefansson E (2005) Screening compliance and visual outcome in diabetes. Acta Ophthalmol Scand 83:687-690

27. Hansson-Lundblad C, Holm K, Agardh CD, Agardh E (2002) A small number of older type 2 diabetic patients end up visually impaired despite regular photographic screening and laser treatment for diabetic retinopathy. Acta Ophthalmol Scand 80:310-315

28. Henricsson M, Tyrberg M, Heijl A, Janzon L (1996) Incidence of blindness and visual impairment in diabetic patients participating in an ophthalmological control and screening programme. Acta Ophthalmol Scand 74:533-538

29. Jeppesen P, Bek T (2004) The occurrence and causes of registered blindness in diabetes patients in Arhus County, Denmark. Acta Ophthalmol Scand 82:526-530

30. Klein R, Kelin BE, Moss SE (1993) Is gross proteinuria a risk factor for the incidence of proliferative diabetic retinopathy? Ophthalmology 100:1140-1146

31. Zimmet P, Alberti KG, Shaw J (2001) Global and societal implications of the diabetes epidemic. Nature 414:782-787

32. King H, Aubert RE, Herman WH (1998) Global burden of diabetes, 1995-2025: prevalence, numerical estimates, and projections. Diabetes Care 21:1414-1431

33. Cook NR (2008) Statistical evaluation of prognostic vs diagnostic models: beyond the ROC curve. Clin Chem 54:17-23

34. van Houwelingen HC (2000) Validation, calibration, revision and combination of prognostic survival models. Stat Med 19:3401-3415 